\title{
Elongated Dihydrogen versus Compressed Dihydride in Osmium
}

\section{Complexes}

Beatriz Eguillor, Miguel A. Esteruelas, * Virginia Lezáun, Montserrat Oliván, and Enrique Oñate

[a] Dr. B. Eguillor, Prof. Dr. M. A. Esteruelas, V. Lezáun, Dr. M. Oliván, Dr. E. Oñate Departamento de Química Inorgánica, Instituto de Síntesis Química y Catálisis Homogénea (ISQCH), Centro de Innovación en Química Avanzada (ORFEO-CINQA), Universidad de Zaragoza - CSIC, 50009 Zaragoza, Spain E-mail: maester@unizar.es

Supporting information for this article is given via a link at the end of the document.

Abstract: Small modifications on the co-ligands of complexes containing two coordinated hydrogen atoms can determine the elongated dihydrogen versus compressed dihydride nature of these species and therefore their chemical behavior. While 2,6-diphenylpyridine favors the formation of the osmium(IV) cation

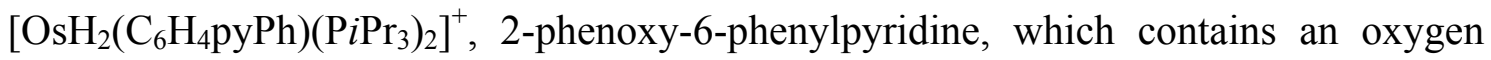
atom between the heterocycle and one of the phenyl groups, stabilizes the osmium(II)

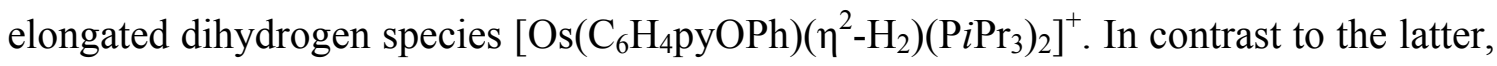
the first of them shows a marked tendency to undergo the reductive elimination of the heterocycle.

Transition metal complexes containing two coordinated hydrogen atoms, which are separated by a distance in the range 1.0-1.6 $\AA$, represent one of the biggest conceptual challenges in the current chemistry. ${ }^{[1]}$ In contrast to the Kubas type complexes (dihydrogens; $\mathrm{d}_{\mathrm{H}-\mathrm{H}}=0.8-1.0 \AA$ ), ${ }^{[2]}$ they are stable towards the dihydrogen dissociation. Furthermore, these compounds also take part in many polyhydride complexes ${ }^{[3]}$ and have proved to participate in interesting catalytic processes involving molecular hydrogen. ${ }^{[4]}$

Two points of view have been used to rationalize their existence: ${ }^{[5]}$ they have been seen as the observable result of the averaging of properties of a dihydrogen form 
and a dihydride form, caused by interconversion of the two forms with an activation energy lower than $10 \mathrm{kcal} \mathrm{mol}^{-1}$, and the most frequent view suggesting an intermediate state in the oxidative addition pathway of a coordinated hydrogen molecule. The latter is consistent with the generally accepted description of the $\mathrm{L}_{n} \mathrm{M}-\mathrm{H}_{2}$ interaction as the combination of donation from the $\mathrm{H}_{2}(\sigma)$ orbital to a metal empty $\mathrm{d}_{\sigma}$ orbital and backdonation from a filled metal $\mathrm{d}_{\pi}$ orbital to the $\mathrm{H}_{2}\left(\sigma^{*}\right)$ orbital. ${ }^{[6]}$ The balance between donation and back-donation determines the oxidative addition degree, which has been fit to the separation between the coordinated hydrogen atoms. ${ }^{[7]}$ Those having separations between 1.0 and $1.3 \AA$ are termed elongated (or stretched) dihydrogens, whereas hydrogen atoms separated between 1.3 and $1.6 \AA$ are considered compressed dihydrides. $^{[3,5 b]}$

The factors determining the dihydrogen or elongated dihydrogen nature of the $\mathrm{MH}_{2}$ units have been widely investigated. Thus, it is currently well established that high oxidation states of the metal center, first row metals, high cationic charges, acidic ligands with a high trans effect disposed trans to the hydrogen atoms, ${ }^{[5 b]}$ and tridentate ligands enforcing L-M-L angles close to $90^{\circ}$ favor the formation of dihydrogen species. ${ }^{[8]}$ On the contrary, low oxidation states, third row metals, neutral complexes, and strong $\pi$-donor ligands favor elongated dihydrogen species. ${ }^{[5 b]}$ On the other hand, the factors governing the formation of elongated dihydrogens versus compressed dihydrides have not been studied mainly because of experimental difficulties, since the transformation between them appears to have a very low activation barrier. ${ }^{[9]}$ Thus, the distinction between elongated dihydrogen and compressed dihydride is generally considered a formal problem. In this communication, we prove that elongated dihydrogen and compressed dihydride are two different types of compounds, with distinct reactivities, and that small adjustments in the co-ligands, away from the metal center, allow the preferential formation of one of the two forms in spite of the line between them is very thin.

The $\mathrm{d}^{2}$-hexahydride complex $\mathrm{OsH}_{6}\left(\mathrm{P}_{i} \mathrm{Pr}_{3}\right)_{2}$ has proved to promote a wide range of $\sigma$-bond activation reactions, ${ }^{[10]}$ including the cleavage of $\mathrm{C}-\mathrm{H}$ bonds. ${ }^{[11]}$ In agreement with this, it reacts with 2,6-diphenylpyridine to give the compressed dihydride 2 (Scheme 1), as a result of the coordination of the heterocycle to the metal center and the ortho- $\mathrm{CH}$ bond activation of both substituents. Complex 2 was isolated as an orange solid in $64 \%$ yield and characterized by X-ray diffraction analysis. The structure (Figure 1) proves the double $\mathrm{C}-\mathrm{H}$ bond activation of the organic substrate with the 
corresponding formation of a C,N,C-pincer ligand. The coordination geometry around the osmium atom can be described as a distorted pentagonal bipyramid with axial phosphines and the hydrides, separated by 1.46(4) $\AA$, lying in the equatorial plane along with the pincer. The compressed dihydride nature of the complex was confirmed by its DFT-optimized structure (B3LYP(GD3)//SDD/6-31G**), and the hydride resonance $(\delta$ -8.05) in the ${ }^{1} \mathrm{H}$ NMR spectrum in $\left[\mathrm{D}_{8}\right]$ toluene. The DFT calculations yield a separation between the hydrides of $1.579 \AA$, which agrees well with that obtained from the X-ray diffraction analysis and the calculated one $(1.49 \AA)$ from the $300 \mathrm{MHz} T_{1}(\min )$ value $(72 \pm 2 \mathrm{~ms})$, at $213 \mathrm{~K}$, of the hydride resonance. ${ }^{[12]}$

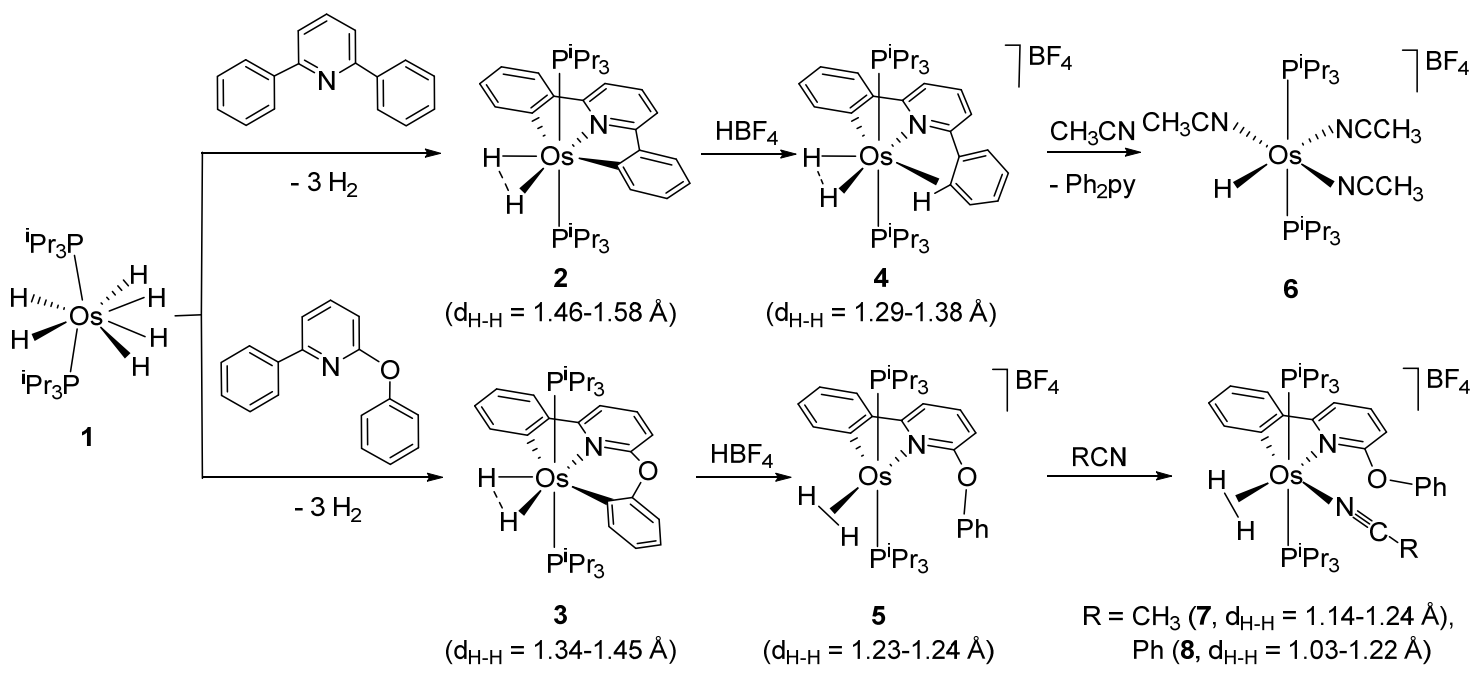

Scheme 1. Compressed dihydride and elongated dihydrogen complexes with 2,6diphenylpyridine and 2-phenoxy-6-phenylpyridine type co-ligands.

The inclusion of a heteroatom between the pyridinic ring and one of its substituents could at first glance increase the steric requirement of the generated pincer in the plane containing the hydride ligands. As a consequence, the hydride ligands should approach, reducing the separation between them, according to that observed in previous cases. ${ }^{[13]}$ Thus, in the search for a shorter compressed dihydride, we performed the reaction of 1 with 2-phenoxy-6-phenyl-pyridine, which contains an oxygen atom between the pyridinic ring and one of the phenyl groups. Treatment of toluene solutions of the hexahydride 1 with 1.0 equiv of the heterocycle, under reflux, for $30 \mathrm{~h}$ affords $\mathbf{3}$, which was isolated as an orange solid in $80 \%$ yield. This compound, which also results 
from the coordination of the pyridinic nitrogen atom to the metal center and the orthometalation of both aromatic substituents, has the same distribution of ligands around the osmium atom as 2 , as supported by its ${ }^{13} \mathrm{C}\left\{{ }^{1} \mathrm{H}\right\},{ }^{31} \mathrm{P}\left\{{ }^{1} \mathrm{H}\right\}$, and ${ }^{1} \mathrm{H} \mathrm{NMR}$ spectra in $\left[\mathrm{D}_{2}\right]$ dichloromethane. The ortho- $\mathrm{CH}$ bond activation of both substituents of the pyridine is reinforced by the ${ }^{13} \mathrm{C}\left\{{ }^{1} \mathrm{H}\right\}$ NMR spectrum, which contains two triplets at $177.1\left({ }^{2} J_{\mathrm{C}-\mathrm{P}}=7.0 \mathrm{~Hz}\right)$ and $137.1\left({ }^{2} J_{\mathrm{C}-\mathrm{P}}=8.0 \mathrm{~Hz}\right) \mathrm{ppm}$, corresponding to the C-donor atoms of the pincer. The equivalent phosphines display a singlet at $1.9 \mathrm{ppm}$, in the ${ }^{31} \mathrm{P}\left\{{ }^{1} \mathrm{H}\right\}$ NMR spectrum, whereas the inequivalent hydrides give rise to an $\mathrm{ABX}_{2}$ spin system $\left(\mathrm{X}={ }^{31} \mathrm{P}\right)$ centered at $-9.90 \mathrm{ppm}$, and defined by $\Delta v=415 \mathrm{~Hz}, J_{\mathrm{A}-\mathrm{B}}=207 \mathrm{~Hz}$, and $J_{\mathrm{AX}}=J_{\mathrm{BX}}=12.3 \mathrm{~Hz}$, in the ${ }^{1} \mathrm{H}$ NMR spectrum at $193 \mathrm{~K}$. The abnormally high value for the $J_{\mathrm{A}-\mathrm{B}}$ coupling constant of two cis-disposed hydride ligands indicates quantum exchange coupling between them. ${ }^{[14]}$ As expected, according to our previous hypothesis, the $300 \mathrm{MHz} T_{1}(\mathrm{~min})$ value of the hydride resonance at $213 \mathrm{~K}(45 \pm 2 \mathrm{~ms})$ is about $30 \mathrm{~ms}$ shorter than that of the hydride resonance of 2 . This value fits with a hydride-hydride separation of $1.37 \AA$, which is in fact about $0.1 \AA$ shorter than in 2 . The shortening is also confirmed by the DFT optimized structure of 3, which reveals a hydride-hydride separation of $1.448 \AA$, also about $0.1 \AA$ shorter than that calculated for 2.

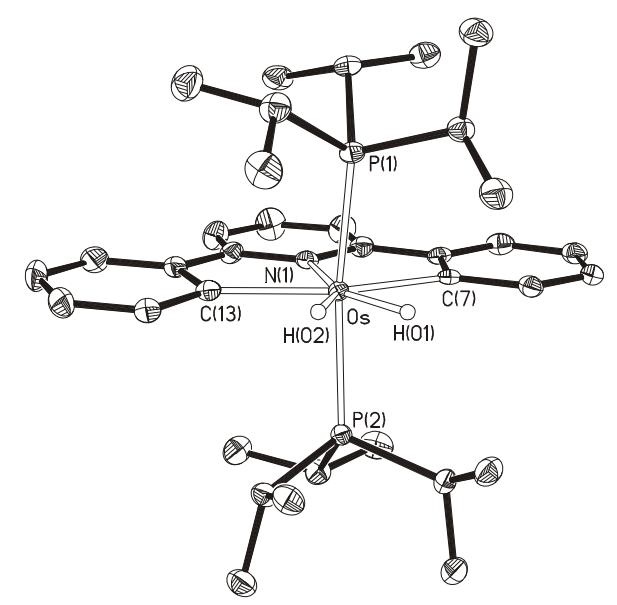

Figure 1. ORTEP diagram of complex 2. Hydrogen atoms (except $\mathrm{H}(01)$ and $\mathrm{H}(02)$ ) are omitted for clarity. Selected bond lengths and angles are given in Table S1 in the Supporting Information.

Complexes $\mathbf{2}$ and $\mathbf{3}$ are both compressed dihydrides. Thus, although there are 0.1 $\AA$ of difference in the separation between their hydrides, they react with $\mathrm{HBF}_{4} \cdot \mathrm{OEt}_{2}$ in the same manner. Treatment of dichloromethane solutions of these compounds with 1.0 
equiv of the acid, at room temperature, produces the formal addition of the proton to one of the C-donor atoms of the pincer, to give the corresponding salts $\mathbf{4}$ and $\mathbf{5}$. In this context the selective protonation of the phenoxy group of 3 should be pointed out, which could be due to the lower stability of the six-membered metalarings with regard to the five-membered metalacycles.

Salt 4 was isolated as a yellow solid in almost quantitative yield and characterized by X-ray diffraction analysis. The structure of the cation (Figure 2) reveals a pentagonal bipyramidal arrangement of donor atoms around the metal center, including an agostic interaction between the osmium atom and the $\mathrm{C}-\mathrm{H}$ bond formed from the protonation. This interaction is strongly supported by the Os-C(13), Os- $\mathrm{H}(13)$, and $\mathrm{C}(13)-\mathrm{H}(13)$ bond lengths of 2.512(3), 1.90(4), and 0.98(4) $\AA$, respectively, which compare well with those reported for other Os-H-C agostic interactions. ${ }^{[15]}$ The $r_{\mathrm{bp}}$ value of $0.72(3) \AA$, which agrees well with those calculated for other $\delta$ agostic interactions, ${ }^{[16]}$ is consistent with the fact of that the interaction persists in $\left[\mathrm{D}_{2}\right]$ dichloromethane at temperatures lower than $203 \mathrm{~K}$. Thus, the INEPT ${ }^{13} \mathrm{C}$ spectrum at this temperature shows a C-H coupling constant of $108 \mathrm{~Hz}$ for a phenyl resonance at $100.6 \mathrm{ppm}$, which is about $40 \mathrm{~Hz}$ lower than the other ${ }^{1} J_{\mathrm{C}-\mathrm{H}}$ coupling constants, whereas the ${ }^{1} \mathrm{H}$ NMR spectrum contains an unusual high field phenyl resonance at $2.92 \mathrm{ppm}$. The hydride ligands lie in the equatorial plane of the bipyramid, along with the heterocycle, separated by $1.29(4) \AA$. This distance agrees well with that found in the DFT-optimized structure, $1.377 \AA$, and is consistent with a low energy thermally activated exchange process involving the inequivalent coordinated hydrogen atoms. Thus, they display only one resonance at $-6.96 \mathrm{ppm}$, even at $183 \mathrm{~K}$, where a $300 \mathrm{MHz} T_{1}$ value of $26 \pm 2 \mathrm{~ms}$ was found. No $T_{1}(\mathrm{~min})$ value was reached. A singlet at $-0.16 \mathrm{ppm}$ for the equivalent phosphines in the ${ }^{31} \mathrm{P}\left\{{ }^{1} \mathrm{H}\right\}$ NMR spectrum is also characteristic for this compound.

The brown salt 5 , which was isolated in $81 \%$ yield, was also characterized by Xray diffraction analysis. Figure 3 shows a view of the cation. In contrast to 3 , it is an unsaturated five-coordinate species, which does not show any agostic interaction. The coordination polyhedron around the metal center can be rationalized as a square pyramid with the metalated phenyl substituent of the pyridine at the apex. At the base, the phosphines are mutually trans disposed, whereas the pyridinic ring lies trans to an elongated dihydrogen ligand. The latter, with the hydrogen atoms separated by $1.18(4)$ $\AA$, is almost perpendicular to the P-Os-P direction. This ligand distribution was 
confirmed by DFT calculations, which yield an optimized structure with a hydrogenhydrogen separation of $1.243 \AA$. The ${ }^{13} \mathrm{C}\left\{{ }^{1} \mathrm{H}\right\},{ }^{31} \mathrm{P}\left\{{ }^{1} \mathrm{H}\right\}$ and ${ }^{1} \mathrm{H}$ NMR spectra of this compound, in $\left[\mathrm{D}_{2}\right]$ dichloromethane, are consistent with the structure shown in Figure 3. Thus, in the ${ }^{13} \mathrm{C}\left\{{ }^{1} \mathrm{H}\right\}$ NMR spectrum, the most noticeable resonance is a triplet $\left({ }^{2} J_{\mathrm{C}-\mathrm{P}}=\right.$ $6.0 \mathrm{~Hz}$ ) at $189.3 \mathrm{ppm}$ corresponding to $\mathrm{C}(1)$. The ${ }^{31} \mathrm{P}\left\{{ }^{1} \mathrm{H}\right\}$ NMR spectrum shows a singlet at $22.1 \mathrm{ppm}$ for the equivalent phosphines, whereas the ${ }^{1} \mathrm{H}$ NMR spectrum contains the characteristic elongated dihydrogen resonance at $-5.22 \mathrm{ppm}$ with a 300 $\mathrm{MHz} T_{1}(\mathrm{~min})$ value of $18 \pm 2 \mathrm{~ms}$, at $213 \mathrm{~K}$, which corresponds to a $\mathrm{H}-\mathrm{H}$ distance of 1.18 $\AA .^{[12]}$ In agreement with this value, a H-D coupling constant of $14.1 \mathrm{~Hz}$ was obtained from the species containing a partially deuterated elongated dihydrogen ligand. ${ }^{[17]}$

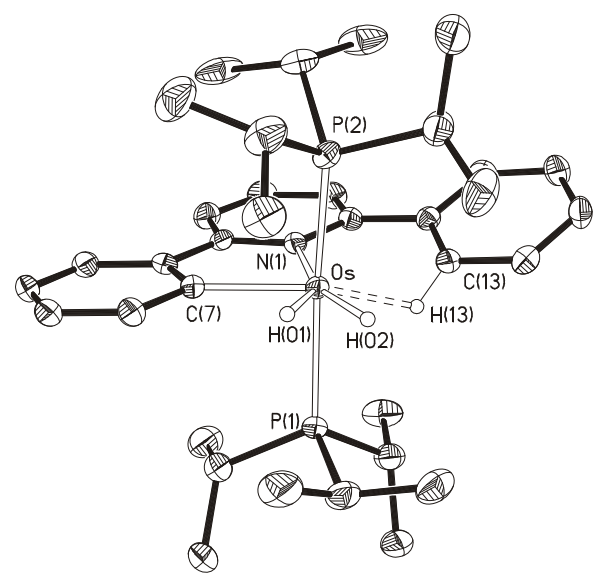

Figure 2. ORTEP diagram of the cation of complex 4. Hydrogen atoms (except $\mathrm{H}(01)$, $\mathrm{H}(02)$ and $\mathrm{H}(13))$ are omitted for clarity. Selected bond lengths and angles are given in Table S2 in the Supporting Information.

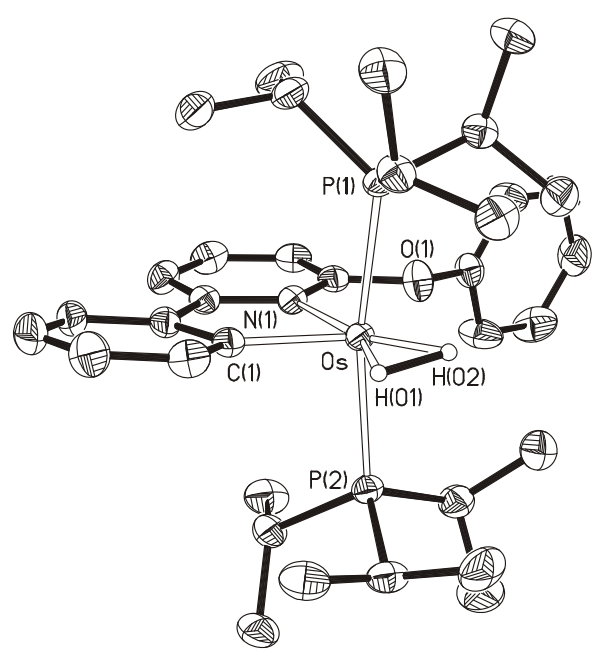


Figure 3. ORTEP diagram of the cation of complex 5. Hydrogen atoms (except H(01) and $\mathrm{H}(02))$ are omitted for clarity. Selected bond lengths and angles are given in Table S3 in the Supporting Information.

Complexes $\mathbf{4}$ and $\mathbf{5}$ have certainly a chemically different nature, according to the previously mentioned data. Complex 4 shows a coordination polyhedron characteristic for a seven-coordinate $\mathrm{d}^{4}$-species. Its saturated character is further consistent with a high oxidation state of the metal center. Thus, in spite of that the separation between its coordinated hydrogen atoms lies at the border line between elongated dihydrogen complexes and compressed dihydride compounds, it should be viewed as a compressed dihydride species. In contrast to $\mathbf{4}$, the separation between the coordinated hydrogen atoms of 5 falls in the middle of the range for elongated dihydrogen compounds. In addition, it should be noted that the coordination polyhedron of 5 has been found in many osmium(II) compounds containing two bulky triisopropylphosphine ligands. ${ }^{[18]}$ The difference in oxidation state between 4 and 5, IV for the first of them and II for the second one, is also supported by their differences in reactivity.

Complex 4 undergoes reductive elimination of 2,6-diphenylpyridine in acetonitrile, under reflux. The resulting 12-valence electron monohydride $\left[\mathrm{OsH}\left(\mathrm{PiPr}_{3}\right)_{2}\right]^{+}{ }^{[19]}$ is trapped by the solvent to afford the previously reported monohydride $6{ }^{[20]}$ In contrast to $\mathbf{4}$, complex 5 coordinates an acetonitrile molecule to give the six-coordinate elongated dihydrogen 7 , which is stable in acetonitrile under reflux; it does not eliminate the heterocycle as $\mathbf{5}$ nor dissociates the hydrogen molecule as should be expected for a Kubas type dihydrogen compound. Similarly to acetonitrile, benzonitrile adds to 5 to form the related complex 8 .

Complexes 7 and 8 were isolated as yellow solids in high yield (80-95\%). The coordination of the nitriles to the metal center was confirmed by means of the X-ray structure of the cation of $\mathbf{8}$ (Figure 4). The geometry around the osmium atom can be rationalized as a distorted octahedron with trans phosphines. In the perpendicular plane, the nitrile is disposed trans to the phenyl group of the chelate, whereas the dihydrogen ligand lies trans to the pyridinic ring with the hydrogen atoms separated by 1.03(5) $\AA$. This distance is similar to that found in the DFT-optimized structure, $1.076 \AA$. The ${ }^{13} \mathrm{C}\left\{{ }^{1} \mathrm{H}\right\},{ }^{31} \mathrm{P}\left\{{ }^{1} \mathrm{H}\right\}$ and ${ }^{1} \mathrm{H}$ NMR spectra for both compounds 7 and $\mathbf{8}$, in $\left[\mathrm{D}_{2}\right]$ dichloromethane, are consistent with the structure shown in Figure 4 . In the 
${ }^{13} \mathrm{C}\left\{{ }^{1} \mathrm{H}\right\}$ NMR spectra, the metalated carbon atom of the chelate group display a triplet $\left({ }^{2} J_{\mathrm{C}-\mathrm{P}}=7 \mathrm{~Hz}\right)$ at about $163 \mathrm{ppm}$. The ${ }^{31} \mathrm{P}\left\{{ }^{1} \mathrm{H}\right\}$ NMR spectra show a singlet at 4 ppm for the equivalent phosphines, whereas the ${ }^{1} \mathrm{H}$ NMR spectra contain the elongated dihydrogen resonance at $-9 \mathrm{ppm}$ with a $300 \mathrm{MHz} T_{1}(\mathrm{~min})$ value of $18 \pm 2 \mathrm{~ms}$, at $215 \mathrm{~K}$. This value agrees with the H-D coupling constants of 13.6 (7) and 14.6 (8) Hz obtained from the corresponding partially deuterated species, which allow to calculate hydrogenhydrogen separations of 1.24 and $1.22 \AA$, respectively. ${ }^{[17]}$

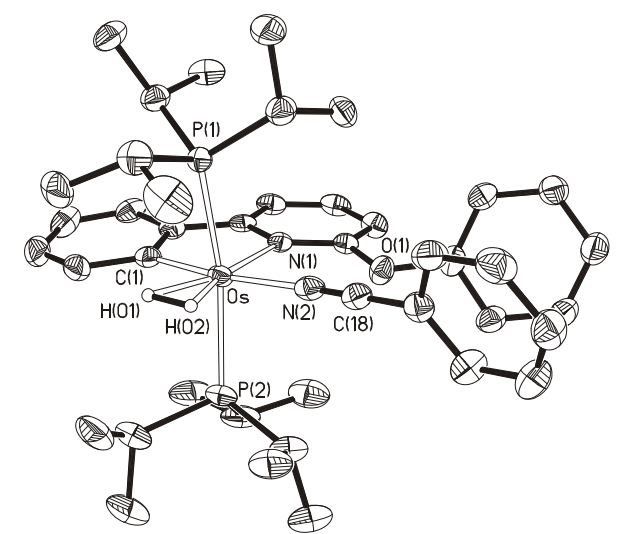

Figure 4. ORTEP diagram of the cation of complex 8. Hydrogen atoms (except $\mathrm{H}(01)$ and $\mathrm{H}(02))$ are omitted for clarity. Selected bond lengths and angles are given in Table S4 in the Supporting Information.

The difference in chemical nature between $\mathbf{4}$ and $\mathbf{5}$ is also revealed by the difference in behavior between both species toward molecular hydrogen. While the saturated osmium(IV) complex 4 is stable in $\left[\mathrm{D}_{2}\right]$ dichloromethane, at room temperature, under a hydrogen atmosphere, for at least $48 \mathrm{~h}$, the unsaturated osmium(II) compound 5 rapidly coordinates molecular hydrogen to afford the bis(dihydrogen) derivative $\mathbf{9}$ (eq 1). The presence of two coordinated hydrogen molecules in this complex is strongly supported by its ${ }^{1} \mathrm{H}$ NMR spectra, in $\left[\mathrm{D}_{2}\right]$ dichloromethane, at temperatures lower than $243 \mathrm{~K}$. These spectra show two dihydrogen resonances at -2.87 and $-11.28 \mathrm{ppm}$ with $400 \mathrm{MHz} T_{1}(\mathrm{~min})$ values of $12 \pm 1$ and $14 \pm 1 \mathrm{~ms}$, at $213 \mathrm{~K}$, which fit with hydrogenhydrogen distances of 1.03 and $1.05 \AA$, respectively. The DFT-optimized structure (See Figure S19) confirms the presence of two coordinated hydrogen molecules in a transphosphine octahedral environment. One of them lies at the perpendicular plane to the POs-P direction $\left(\mathrm{d}_{\mathrm{H}-\mathrm{H}}=1.071 \AA\right)$, along with the chelate ligand, whereas the other one is almost parallel to the P-Os-P direction $\left(\mathrm{d}_{\mathrm{H}-\mathrm{H}}=0.868 \AA\right.$ ). At temperatures higher than $243 \mathrm{~K}$, the coordinated hydrogen molecules exchange their positions. Under vacuum, 
one of the hydrogen molecules is released from the metal center, suggesting that at least one of the dihydrogen ligands is of Kubas type, in agreement with the DFT-optimized structure.

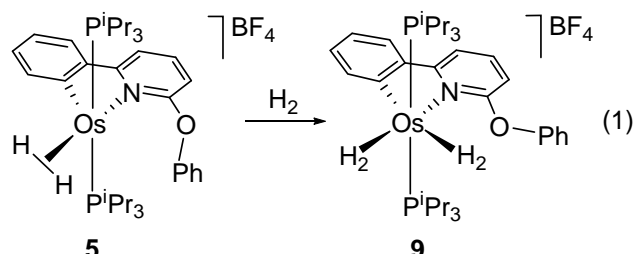

In conclusion, when a hydrogen molecule interacts with an unsaturated metal center, it is adhered (Kubas type dihydrogen), bonded (elongated dihydrogen), or broken (compressed dihydride). Although the border between the metal-dihydrogen marriage and the rupture of the hydrogen-hydrogen bond is very subtle, the resulting species of both processes have different chemical nature and therefore different chemical behavior. The formation of one or the other can be certainly governed by means of the introduction of fine modifications in the co-ligands of the complexes, away from the metal center. These changes can include the introduction of an oxygen atom between one of the pyridyl-phenyl bonds of 2,6-diphenylpyridine, as is demonstrated here.

\section{Acknowledgements}

Financial support from the MINECO of Spain (Project CTQ2014-52799-P), the Diputación General de Aragón (E-35), FEDER, and the European Social Fund is acknowledged.

\section{References}

[1] a) D. M. Heinekey, A. Lledós, J. M. Lluch, Chem. Soc. Rev. 2004, 33, 175-182; b)

R. H. Morris, Coord. Chem. Rev. 2008, 252, 2381-2394.

[2] a) G. J. Kubas in Metal Dihydrogen and $\sigma$-Bond Complexes: Structure, Theory and Reactivity, Kluwer, New York, 2001; b) R G. J. Kubas, Chem. Rev. 2007, 107, $4152-4205$.

[3] M. A. Esteruelas, A. M. López, M. Oliván, Chem. Rev. 2016, 116, 8770-8847. 
[4] a) M. A. Esteruelas, L. A. Oro, Chem. Rev. 1998, 98, 577-588; b) G. Jia, Z. Lin, C. P. Lau, Eur. J. Inorg. Chem. 2003, 2551-2562; c) A. Rossin, M. Peruzzini, Chem. Rev. 2016, $116,8848-8872$.

[5] a) P. G. Jessop, R. H. Morris, Coord. Chem. Rev. 1992, 121, 155-284; b) R. H. Crabtree, Chem. Rev. 2016, 116, 8750-8769, c) R. N. Perutz, S. Sabo-Etienne, Angew. Chem. Int. Ed. 2007, 46, 2578-2592.

[6] G. J. Kubas, J. Organomet. Chem. 2001, 635, 37-68.

[7] a) D. M. Heinekey, W. J. Oldham, Jr., Chem. Rev. 1993, 93, 913-926; b) G. J. Kubas, J. Organomet. Chem. 2014, 751, 33-49.

[8] a) R. Castro-Rodrigo, M. A. Esteruelas, A. M. López, M. Oliván, E. Oñate, Organometallics 2007, 27, 4498-4509; b) M. Baya, M. A. Esteruelas, M. Oliván, E. Oñate, Inorg. Chem. 2009, 48, 2677-2686.

[9] G. Barea, M. A. Esteruelas, A. Lledós, A. M. López, J. I. Tolosa, Inorg. Chem. 1998, $37,5033-5035$.

[10] a) M. A. Esteruelas, J. García-Raboso, M. Oliván, E. Oñate, Inorg. Chem. 2012, 51, 5975-5984; b) M. A. Esteruelas, J. García-Raboso, M. Oliván, Inorg. Chem. 2012, 51, 9522-9528; c) L. Casarrubios, M. A. Esteruelas, C. Larramona, J. G. Muntaner, M. Oliván, E. Oñate, M. A. Sierra, Organometallics 2014, 33, 1820-1833; d) T. Bolaño, M. A. Esteruelas, M. P. Gay, E. Oñate, I. M. Pastor, M. Yus, Organometallics 2015, 34, 3902-3908; e) L. Casarrubios, M. A. Esteruelas, C. Larramona, A. Lledós, J. G. Muntaner, E. Oñate, M. A. Ortuño, M. A. Sierra, Chem. Eur. J. 2015, 21, 16781-16785. [11] a) M. A. Esteruelas, A. B. Masamunt, M. Oliván, E. Oñate, M. Valencia, J. Am. Chem. Soc. 2008, 130, 11612-11613; b) O. Crespo, B. Eguillor, M. A. Esteruelas, I. Fernández, J. García-Raboso, M. Gómez-Gallego, M. Martín-Ortiz, M. Oliván, M. A. Sierra, Chem. Commun. 2012, 48, 5328-5330; c) M. A. Esteruelas, I. Fernández, M. Gómez-Gallego, M. Martín-Ortiz, P. Molina, M. Oliván, F. Otón, M. A. Sierra, M. Valencia, Dalton Trans. 2013, 42, 3597-3608; d) R. G. Alabau, B. Eguillor, J. Esler, M. A. Esteruelas, M. Oliván, E. Oñate, J.-Y. Tsai, C. Xia, Organometallics 2014, 33, 55825596.

[12] The H-H distances were calculated from the $T_{1}(\min )$ values both applying the equation $R_{\mathrm{H}-\mathrm{H}}=129.18 / r_{\mathrm{H}-\mathrm{H}}{ }^{6}$, where $R_{\mathrm{H}-\mathrm{H}}=R_{\mathrm{n}}-R^{*}\left(R_{\mathrm{n}}\right.$ is the relaxation rate due to the dipole-dipole interaction, and is equal to $1 / T_{1}(\min )$ at $300 \mathrm{MHz}$, and $R^{*}$ is the relaxation rate due to all other relaxation contributors of the molecule and is estimated to be $2.5 \mathrm{~s}^{-1}$. See: A. Castillo, M. A. Esteruelas, E. Oñate, N. Ruiz, J. Am. Chem. Soc. 1997, 119, 
9691-9698), or the equation $r_{\mathrm{H}-\mathrm{H}}=5.815\left(T_{1}(\min ) / v\right)^{1 / 6}\left(T_{1}(\min )\right.$ in seconds, $v$ in $\left.\mathrm{MHz}\right)$, assuming no rotation of the $\mathrm{H}_{2}$ unit. See: M. T. Bautista, E. P. Cappellani, S. D. Drouin, R. H. Morris, C. T. Schweitzer, A. Sella, J. Zubkowski, J. Am. Chem. Soc. 1991, 113, $4876-4887$.

[13] L. Casarrubios, M. A. Esteruelas, C. Larramona, J. G. Muntaner, E. Oñate, M. A. Sierra, Inorg. Chem. 2015, 54, 10998-11006.

[14] S. Sabo-Etienne, B. Chaudret, Chem. Rev. 1998, 98, 2077-2091.

[15] a) M. A. Esteruelas, F. J. Lahoz, L. A. Oro, E. Oñate, E. Sola, J. Am. Chem. Soc. 1996, 118, 89-99; b) T. B. Wen, Z. Y. Zhou, C.-P. Lau, G. Jia, Organometallics 2000, 19, 3466-3468; c) R. Castro-Rodrigo, M. A. Esteruelas, A. M. López, E. Oñate, Organometallics 2008, 27, 3547-3555; d) B. Eguillor, M. A. Esteruelas, I. Fernández, M. Gómez-Gallego, A. Lledós, M. Martín-Ortiz, M. Oliván, E. Oñate, M. A. Sierra, Organometallics 2015, 34, 1898-1910; e) B. Eguillor, M. A. Esteruelas, V. Lezáun, M. Oliván, E. Oñate, J.-Y. Tsai, C. Xia, Chem. Eur. J. 2016, 22, 9106-9110.

[16] $r_{\mathrm{bp}}$ is the covalent radius of the $\mathrm{C}-\mathrm{H}$ bonding electrons and can be calculated according to the equation $r_{\mathrm{bp}}=d_{\mathrm{bp}}-r_{\mathrm{M}}$, where $d_{\mathrm{bp}}$ is the distance from the metal to the $\mathrm{C}-\mathrm{H}$ bonding electron pair and $r_{\mathrm{M}}$ is the covalent radius of the metal. See: R. H. Crabtree, E. M. Holt, M. Lavin, S. M. Morehouse, Inorg. Chem. 1985, 24, 1986-1992. [17] $d_{\mathrm{H}-\mathrm{H}}=150-1.92 J_{\mathrm{H}-\mathrm{D}}$. See reference $1 \mathrm{~b}$.

[18] a) M. A. Esteruelas, L. A. Oro, Adv. Organomet. Chem. 2001, 47, 1-59; b) M. A. Esteruelas, A. M. López, M. Oliván, Coord. Chem. Rev. 2007, 251, 795-840.

[19] M. L. Buil, M. A. Esteruelas, K. Garcés, J. García-Raboso, M. Oliván, Organometallics 2009, 28, 4606-4609.

[20] a) K.-T. Smith, M. Tilset, R. Kuhlman, K. G. Caulton, J. Am. Chem. Soc. 1995, 117, 9473-9480; b) M. A. Esteruelas, S. Fuertes, M. Oliván, E. Oñate, Organometallics 2009, $28,1582-1585$ 


\section{Scheme and Figure legends}

Scheme 1. Compressed dihydride and elongated dihydrogen complexes with 2,6diphenylpyridine and 2-phenoxy-6-phenylpyridine type co-ligands.

Figure 1. ORTEP diagram of complex 2. Hydrogen atoms (except $\mathrm{H}(01)$ and $\mathrm{H}(02)$ ) are omitted for clarity. Selected bond lengths and angles are given in Table S1 in the Supporting Information.

Figure 2. ORTEP diagram of the cation of complex 4. Hydrogen atoms (except $\mathrm{H}(01)$, $\mathrm{H}(02)$ and $\mathrm{H}(13))$ are omitted for clarity. Selected bond lengths and angles are given in Table S2 in the Supporting Information.

Figure 3. ORTEP diagram of the cation of complex 5. Hydrogen atoms (except $\mathrm{H}(01)$ and $\mathrm{H}(02))$ are omitted for clarity. Selected bond lengths and angles are given in Table S3 in the Supporting Information.

Figure 4. ORTEP diagram of the cation of complex 8. Hydrogen atoms (except $\mathrm{H}(01)$ and $\mathrm{H}(02))$ are omitted for clarity. Selected bond lengths and angles are given in Table S4 in the Supporting Information.

\section{Entry for the Table of Contents}

Small modifications on the co-ligands of complexes containing two coordinated hydrogen atoms can determine the elongated dihydrogen versus compressed dihydride nature of these species and therefore their chemical behavior.

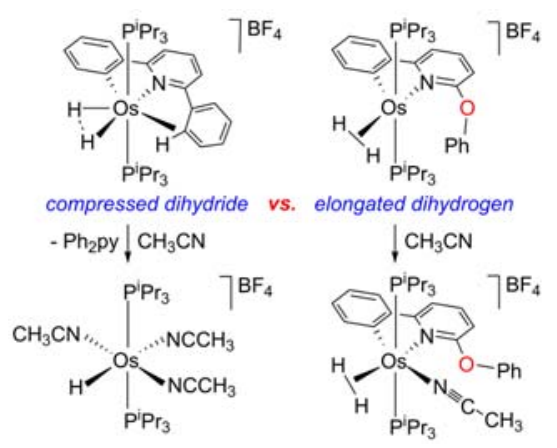

Keywords: osmium $\bullet$ dihydrogen $\bullet$ hydride $\bullet$ agostic interactions $\bullet$ C-H activation 